\title{
INCIDENCE OF CONGENITAL PYLORIC STENOSIS IN BIRTH SERIES
}

\author{
Joseph R. Huguenard and G. E. (Ned) Sharples \\ School of Public Health, The University of Michigan, \\ Ann Arbor, Mich. 48104
}

(Received 27 March 1972; in final form 23 August 1972)

CONGENITAL hypertrophic pyloric stenosis has been linked with primogeniture in many reports since Still [1] first suggested that its incidence might be associated with birth rank. Principal contributors to this view are: Ford, Ross and Brown [2]; Cockayne and Penrose [3]; McKeown, MacMahon and Record [4, 5]. Most recently this view has been advanced by Shim, Campbell and Wright [6]. These authors have used various methods in reaching this conclusion. Ford, Ross and Brown [2] assembled a large group of pyloric stenosis cases and compared the percent distribution of birth ranks within the general population as presented by census data for the city of Toronto and the province of Ontario, Canada. Cockayne and Penrose [3] followed the method of Greenwood and Yule, in the Journal of Royal Statistical Society, January 1914, to generate an expected proportion of cases at each birth rank for their study population, to which they compared their actual proportion of cases found. McKeown, MacMahon and Record [4] used a control group of randomly selected live births in the same years in the same city to compare proportionate distributions of birth ranks among afflicted and unafflicted groups. Shim, Campbell and Wright [6] compared the birth order distribution of their case material to Hawaii population data.

A few investigators have dissented from the conclusion that pyloric stenosis is related to primogeniture. Delprat and Pflueger [7] have commented that comparisons are questionable because of inadequate information about the proportion of firstborn among all living children. Benson and Warden [8], using a group of 707 cases, found the proportion of firstborn did not differ from the general United States population, estimating the number of firstborn from average family size.

Most data used to investigate the question have been derived from clinic sources, which include information about the sibships only at times of patient treatment or follow-up. This means that most families had incomplete sibships at the times information was collected.

In previous work the authors have shown that efforts to relate birth order to incidence of congenital pathology reach inaccurate conclusions when based on information which is temporally limited to an incomplete accounting of the full series 
of births (Sharples and Huguenard, Effects of Incomplete Data on Apparent Relations Between Parity and Incidence of Congenital Malformations, available from the authors). The research reported here was done to further test the importance of complete birth series information. Pyloric stenosis was chosen because epidemiologic reports indicating higher incidence among primogenitures are at variance with data suggesting genetic etiology, which logically would provide no biological basis for a skewed distribution of cases within a series of births.

The records of all cases of congenital hypertrophic pyloric stenosis treated at the University Hospital, Ann Arbor, Michigan, from 1940 through 1955 were reviewed. These years were chosen so that mothers would have since had time to complete their years of childbearing. (Data were collected in the last months of 1970.) Those cases which were definitely diagnosed at surgery were selected, the records abstracted, and the parents of these children were questioned by mail. Follow-up of all 85 cases identified was attempted. Mothers were asked to report the total number of children ever born to them and any surgery for pyloric stenosis among their other children. A cover letter identified the patient as having had pyloric stenosis, and the language of the questions and responses included laymen's terms, so that respondents were able to report accurately about occurrence.

A total of 55 cases of pyloric stenosis in 51 families having a total of 203 children were assembled. This response constituted 61 per cent of all families questioned. The responding families included pyloric stenosis cases evenly distributed through the 1940-55 period, and the time of follow-up ranged from 15 to $29 \mathrm{yr}$ after identifying surgery. For practical purposes, this group consisted of completed families.

Our analysis consisted of comparing observed distributions of afflicted children to an expected distribution. The expected numbers were generated by actual random distribution of the known number of cases into the known number of birth order positions such that every family had at least one afflicted individual who could occur with equal chance in any of the birth order positions available in that family. The additional afflicted individuals, exceeding one per family, were randomly distributed among all remaining birth order positions such that each unoccupied birth order position in the total group had an equal chance to be occupied by any of the additional afflicted individuals. A series of 1000 such random distributions were generated and the mean numbers of afflicted individuals per birth order position were computed together with their standard deviations. An IBM 360 computer was used to generate the random numbers and distribute cases within the framework of the observed population. A manual for this procedure is being written.

Observed data were compared to the random distributions adopting the criteria that observed frequencies exceeding two standard deviations of the random mean frequency were unlikely to occur by chance.

A further test was conducted using data previously published by others. Our re-analyses of the reports of Cockayne and Penrose [3]; McKeown, MacMahon and Record [5]; and Danis [9] appear in Tables 2, 3 and 4, and the accompanying graphs. These re-analyses were done using our technique of comparing observed to expected frequencies. The published data were recoded to eliminate miscarriages and twins, retaining focus on birth position. Correction for twins left in the data can be made but is cumbersome. Elimination does not change the distributions and is preferred for ease of method use by other investigators. 
TABle 1. Michigan data: Distribution of OBSERVED and eXPeCted CASES OF PYLORIC STENOSIS WITH LIMITS OF CONFIDENCE $2 \sigma$. FAMILIES CONTAINING TWIN BIRTHS HAVE BEEN ELIMINATED

\begin{tabular}{ccccc}
\hline $\begin{array}{c}\text { Birth } \\
\text { position }\end{array}$ & $\begin{array}{c}\text { Observed } \\
\text { cases }\end{array}$ & Means & $\begin{array}{c}\text { Expected cases* } \\
-2 \sigma\end{array}$ & $+2 \sigma$ \\
\hline 1 & 15 & 16.2 & 9.9 & 22.5 \\
2 & 19 & 15.2 & 8.7 & 21.7 \\
3 & 11 & 12.0 & 6.4 & 17.6 \\
4 & 8 & 6.1 & 1.7 & 10.5 \\
5 & 1 & 3.0 & -0.1 & 6.1 \\
6 & 0 & 1.2 & -0.8 & 3.2 \\
7 & 0 & 0.6 & -0.8 & 2.0 \\
8 & 1 & 0.3 & -0.6 & 1.2 \\
9 & 0 & 0.3 & -0.6 & 1.2 \\
10 & 0 & 0.1 & -0.5 & 0.7 \\
11 & 0 & 0.1 & -0.5 & 0.7 \\
\hline
\end{tabular}

*Based on 1000 serial random distributions

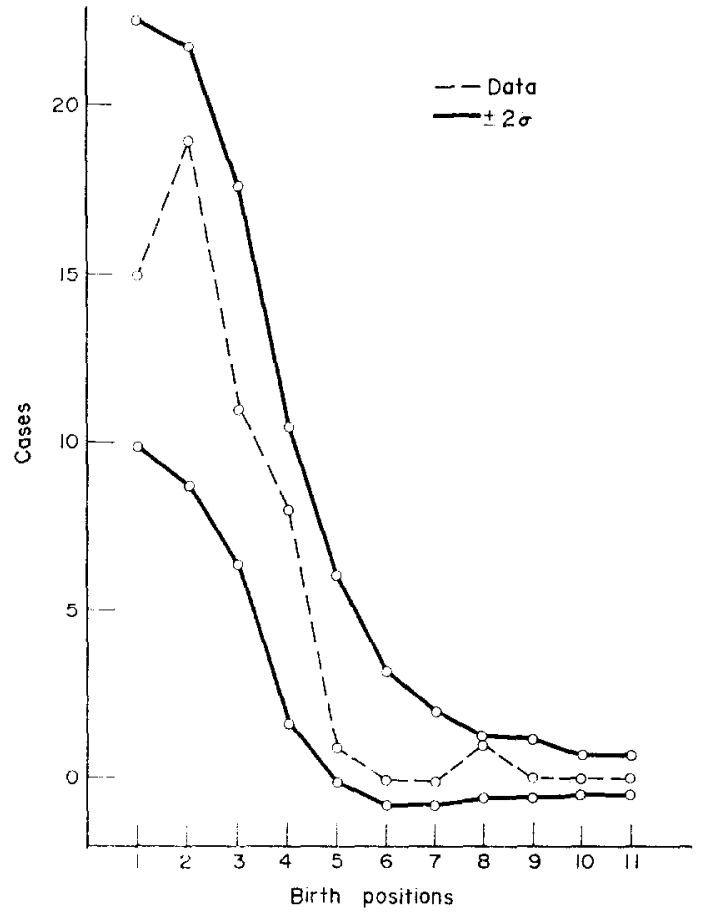

FIG. 1

\section{DISCUSSION}

Two basic approaches are appropriate in seeking to determine whether birth order is related to incidence of disease. The birth order distribution of disease can be compared to the birth order distribution of a control sample, or, alternatively, to an expected distribution.

The first approach presents the problem of defining and collecting data on a parallel population for comparison, especially hard to do when dealing with a disease 
Table 2. Danis data: Distribution of ObServed and eXPeCted cases OF PYLORIC STENOSIS WITH LIMITS OF CONFIDENCE $2 \sigma$

\begin{tabular}{ccccc}
\hline $\begin{array}{c}\text { Birth } \\
\text { position }\end{array}$ & $\begin{array}{c}\text { Observed } \\
\text { cases }\end{array}$ & Means & $\begin{array}{c}\text { Expected cases* } \\
-2 \sigma\end{array}$ & $+2 \sigma$ \\
\hline 1 & 51 & 59.0 & 50.9 & 67.1 \\
2 & 38 & 33.0 & 25.1 & 40.9 \\
3 & 14 & 12.8 & 7.0 & 18.6 \\
4 & 7 & 6.5 & 2.2 & 10.8 \\
5 & 4 & 3.4 & 0.3 & 6.5 \\
6 & 3 & 2.4 & -0.3 & 5.1 \\
\hline
\end{tabular}

*Based on 1000 serial random distributions

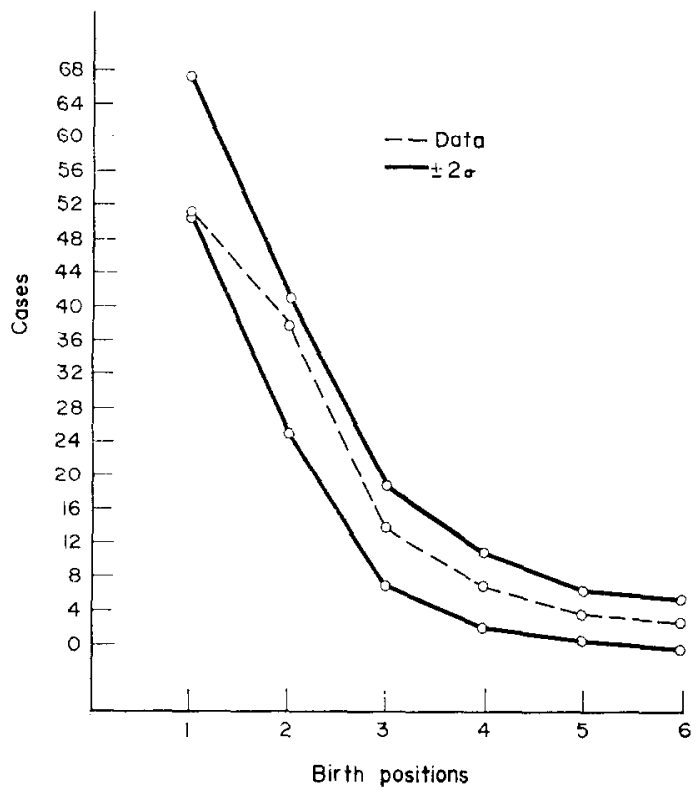

Fig. 2

relatively uncommon in the general population. Using this approach it is extremely difficult to be sure that variations which occur between the control group and the known cases are not caused by basic differences in the groups which work against legitimate and useful comparison. This is especially so when parameters of the populations are unknown or disease etiology is inexhaustively known. Ethnic, income, age, education or social status factors may influence selection into a population or associate with incidence of pathology and distort findings about variable relationships without being causatively related to the disease. Because the afflicted populations are much smaller than the general population, the effects of such differences cannot be easily estimated.

In previous work using the control groups method, no correction was made for the possible variation in family size, or in the proportion of completed families, in general populations compared to clinic populations. This variation is also expressed in differences in the proportionate distribution of birth order positions. The distri- 
Table 3. Cockayne and Penrose data: Distribution of observed AND EXPECTED CASES OF PYLORIC STENOSIS WITH LIMITS OF CONFIDENCE $2 \sigma$.

FAMILIES CONTAINING TWIN BIRTHS HAVE BEEN ELIMINATED

\begin{tabular}{ccrrr}
\hline $\begin{array}{c}\text { Birth } \\
\text { position }\end{array}$ & $\begin{array}{c}\text { Observed } \\
\text { cases }\end{array}$ & Means & $\begin{array}{c}\text { Expected cases* } \\
-2 \sigma\end{array}$ & $+2 \sigma$ \\
\hline 1 & 114 & 115.5 & 104.4 & 126.6 \\
2 & 51 & 57.7 & 46.5 & 68.9 \\
3 & 20 & 20.7 & 14.0 & 28.4 \\
4 & 12 & 8.5 & 3.5 & 13.5 \\
5 & 5 & 3.5 & 0.2 & 6.8 \\
6 & 5 & 2.1 & -0.6 & 4.8 \\
7 & 2 & 1.4 & -0.8 & 3.6 \\
8 & 1 & 0.5 & -0.9 & 1.9 \\
9 & 0 & 0.1 & -0.5 & 0.7 \\
\hline
\end{tabular}

*Based on 1000 serial random distributions

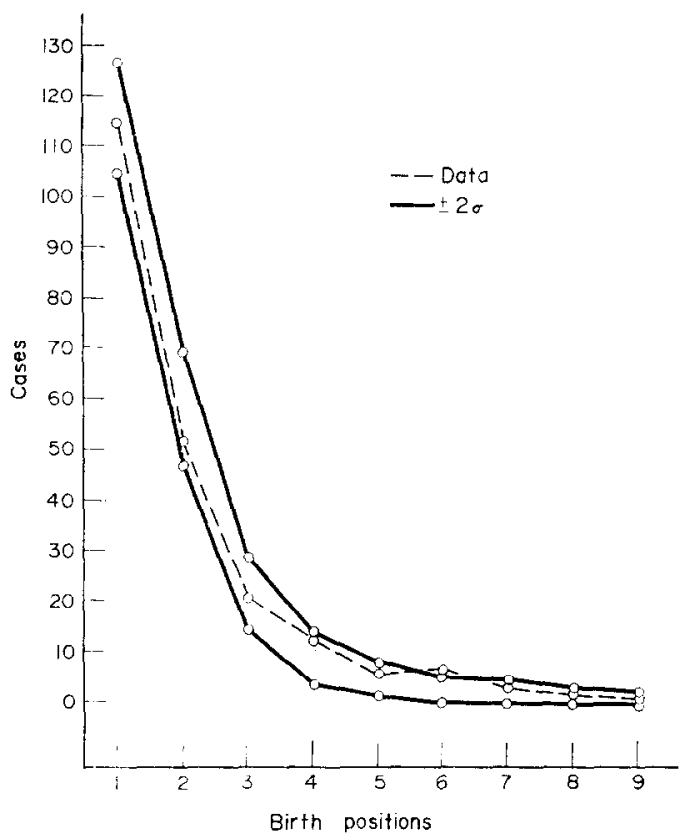

FIG. 3

butions of available birth order positions into which afflicted and normal children could be born must be the same if a comparison is to be made. It is not appropriate to assume they are the same. This difference does not average out and ignoring its effect significantly distorts conclusions. Any data which is cross-sectional, or is collected at only one point in time, about a population of families into which more children are likely to be born has this limitation.

In the second approach comparisons are made between a known and an expected distribution. The expected distribution can be generated using the parameters of the observed population. Specifically, it is important that in both the observed and expected groups, the proportion of all positions which are available at each birth 
TABle 4. MCKeown, MaCMahon and Record data: Distribution of OBSERVED AND EXPECTED CASES OF PYLORIC STENOSIS WITH LIMITS OF CONFIDENCE $2 \sigma$. FAMILIES CONTAINING TWIN BIRTHS HAVE BEEN ELIMINATED

\begin{tabular}{ccrrr}
\hline $\begin{array}{c}\text { Birth } \\
\text { position }\end{array}$ & $\begin{array}{c}\text { Observed } \\
\text { cases }\end{array}$ & Means & $\begin{array}{c}\text { Expected cases* } \\
-2 \sigma\end{array}$ & $+2 \sigma$ \\
\hline 1 & 246 & 271.8 & 255.9 & 287.7 \\
2 & 131 & 127.7 & 111.6 & 143.8 \\
3 & 56 & 45.2 & 34.2 & 56.2 \\
4 & 19 & 16.2 & 9.4 & 23.0 \\
5 & 15 & 6.3 & 1.7 & 10.9 \\
6 & 1 & 2.4 & -0.5 & 5.3 \\
7 & 1 & 1.6 & -1.3 & 3.9 \\
8 & 1 & 0.8 & -0.9 & 2.5 \\
9 & 0 & 0.4 & -0.7 & 1.5 \\
10 & 3 & 0.4 & -0.7 & 1.5 \\
11 & 0 & 0.1 & -0.5 & 0.7 \\
12 & 0 & 0.1 & -0.5 & 0.7 \\
\hline
\end{tabular}

*Based on 1000 serial random distributions

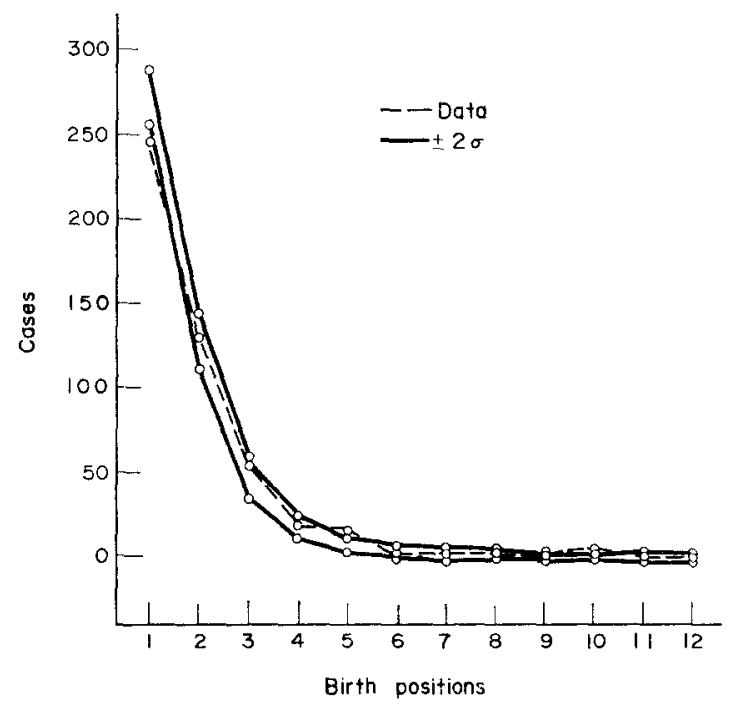

FIG. 4

rank be the same, that the total afflicted individuals and the total of all birth positions be the same. With such data for a known population, a random distribution, with its confidence limits, of afflicted cases can be actually constructed so that each afflicted individual has an equal chance to occupy any birth order position within his family. Using the known families to obtain the limits of the distribution has the advantage that no new factors, social or medical, are introduced by employment of a special comparison group.

The previously mentioned shortcoming of the other analyses also applies to this approach, that it is inaccurate for families into which all children of the series have not yet been born. It becomes more accurate with older mothers and with longer periods for which information is available. We have attempted to assemble completed families by following up cases a considerable time after the identifying diagnosis. 
The data published by other authors which we re-analyzed had been collected after the birth of the propositus and consequently was amenable to analysis by our method. Although a longer follow-up period would have been preferable, analysis revealed no significant distortion of findings due to short follow-up.

To estimate the influence of having only partial or truncated family information in the data from other authors, two methods were used. First, families in which the last birth had occurred five or more years prior to the follow-up data collection were isolated. Second, families in which the mother was $40 \mathrm{yr}$ of age or older at the time of follow-up were selected. These methods tend to eliminate families in which additional children are more likely to be born. Therefore, in both of these subgroups the sibships were more complete than in each respective total data group. The distributions of cases in the subgroups, which contained the more completed sibships of each study, showed little deviation from the distributions of the respective total data groups from which they were isolated, and they showed no increase of first birth position cases compared to the expected. These findings indicate that the elapsed time before follow-up was sufficient to eliminate most of the biases of incomplete sibships which have been observed in data which truncates the sibship at the birth of the afflicted child.

Our finding that no relationship occurs between primogeniture and occurrence of pyloric stenosis in the Michigan data appears to be supported by the same finding in other data, upon re-analysis. These results appear to be conclusive and replicable. They suggest a need for reorientation of thinking about incidence of pyloric stenosis with respect to primogeniture.

\section{SUMMARY}

Conflicting reports of the incidence of congenital hypertrophic pyloric stenosis have incriminated genetic factors and the first birth position. A survey of 55 cases in families with completed birth series was made. Random distributions of cases within birth series were found for the primary University of Michigan data and for data from three secondary sources. Reconsideration is suggested regarding factors influencing incidence, types of data and methods of analysis used in previous work.

Acknowledgements--The authors gratefully acknowledge the assistance of the Department of Pediatrics, University of Michigan Medical School and particularly the help of William J. Oliver, M.D., Department Chairman and Patricia O'Connor, M.D., Director, Pediatric Outpatient Cinic, University Hospital.

\section{REFERENCES}

1. Still GF: Place-in-family as a factor in disease. Lancet 2: 795, 1927

2. Ford N, Ross MA, Brown A: Primogeniture as an etiologic factor in pyloric stenosis. Am $\mathbf{J}$ Dis Child 61: 747-751, 1941

3. Cockayne EA, Penrose LS: The genetics of congenital pyloric stenosis. Ohio J Sci 43: 1-16, 1943

4. Mckeown T, MacMahon B, Record RG: The incidence of congenital pyloric stenosis related to birth rank and maternal age. Ann Eugen 16: 249-259, 1951a

5. Mckeown T, MacMahon B, Record RG: The familial incidence of congenital pyloric stenosis. Ann Eugen 16: 260-281, 1951b

6. Shim WKT, Campbell A, Wright SW: Pyloric stenosis in the racial groups of Hawaii. J Pediat $76: 89-93,1970$

7. Delprat GD, Pflueger O: Pyloric stenosis not a disease of first born. Calif Med 68: 76, 1948

8. Benson $\mathrm{CD}$, Warden $\mathrm{MJ}$ : Seven hundred and seven cases of congenital hypertrophic pyloric stenosis. Surg Gynec Obstet 105: 348-354, 1957

9. Danis A: La frequence de la stenose hypertrophique du pylore n'augmente pas avec le nombre de grossesses. Acta Paediat Belg 11: 248-252, 1957 